\title{
Extended Fenske-Hall LCAO MO Calculations for Mixed Methylene Dihalides
}

\author{
Igor Novak \\ Department of Physics, University of Birmingham, Birmingham B15 2TT, UK \\ Z. Naturforsch, 43 a, $851-854$ (1988); received July 4, 1988
}

The electronic structure of mixed methylene dihalides $\mathrm{CH}_{2} \mathrm{XY}(\mathrm{X}, \mathrm{Y}=\mathrm{F}, \mathrm{Cl}, \mathrm{Br}, \mathrm{I})$ has been
studied using extended Fenske-Hall LCAO MO method. The comparison with available photoelec-
tron spectra confirmes previous assignments of all bands with binding energies $<100 \mathrm{eV}$. The
electronic structure changes occurring upon varying the halogen substituents are discussed.

\section{Introduction}

The halomethanes constitute an interesting class of compounds for several reasons. They have important technological applications (refrigeration, propellants) and are presently considered to be significant air pollutants. Also, they represent a prototype of halogen substituted molecules. The electronic structure of some halomethanes has been investigated previously by experimental and theoretical methods. However the electronic structure of halomethane molecules with low symmetry $\left(C_{s}\right.$ and $C_{1}$ point groups) remains to be studied in any detail. In this work we have chosen to study methylene dihalides $\left(\mathrm{CH}_{2} \mathrm{XY}\right)$ mainly for two reasons. Firstly, the good quality photoelectron spectra of $\mathrm{CH}_{2} \mathrm{FCl}, \mathrm{CH}_{2} \mathrm{BrCl}$ and $\mathrm{CH}_{2} \mathrm{ClI}$ reported some time ago and assigned through purely empirical considerations $[1,2]$ allow a comparison to be made with the calculated electronic structure. Secondly, we wished to test the applicability of extended Fenske-Hall (EFH) LCAO MO method in molecules of low symmetry containing several heavy atoms. This method has so far been mainly used to study the electronic structure of inorganic metal complexes. The EFH method has previously been employed in the calculation of inner-shell binding energies of fluoromethanes with some success [3].

\section{Method of Calculation}

The EFH method used in this work was an all electron method employing good quality extended

Reprint requests to Dr. I. Novak, 20 Ashfield House, Grosvenor Avenue, London N 52 NU, U.K. basis sets. Calculations with two different kinds of basis sets were performed for six methylene dihalides. The basis sets adopted in the calculation were of double zeta and Hartree-Fock quality [4]. The EFH method does not involve any adjustable or empirical parameters, so the resulting eigenvalues and eigenvectors will be sensitive to the choice of basis functions and molecular geometry only. In the present work, experimentally determined molecular geometries were used where ever possible [5-9]. In case of $\mathrm{CH}_{2} \mathrm{FI}$, for which no experimental data exist, the molecular structure adopted was derived by assuming the $\mathrm{CH}_{2} \mathrm{ClI}$ geometry [5] and the $\mathrm{CF}$ bond length taken from data on $\mathrm{CH}_{2} \mathrm{FBr}$ [6]. The molecular coordinate system was defined in such a way that the $y z$ plane was the plane of symmetry $\left(\mathrm{C}_{\mathrm{s}}\right.$ point group).

It is worth mentioning that the calculations are non relativistic and electronic structure correlations are based on Koopmans' approximation. The inclusion of relativistic effects will possibly induce some energy shifts in predominantly iodine lone pair type molecular orbitals. Fully relativistic MO calculations on molecules with several heavy atoms and low molecular symmetry are rare at present due to the necessity of introducing very large basis sets and the lack of symmetry simplifications which help in the evaluation of matrices and electron integrals.

\section{Results and Discussion}

The eigenvalues obtained from the calculations for six $\mathrm{CH}_{2} \mathrm{XY}$ molecules using HF STO basis sets are presented in Table 1. The differences in eigenvalues and eigenvectors obtained when using double zeta

0932-0784/88/1000-0851 \$01.30/0. - Please order a reprint rather than making your own copy. 
Table 1. Binding energies (eV) for $\mathrm{CH}_{2} \mathrm{XY}^{\mathrm{a}, \mathrm{b}}$.

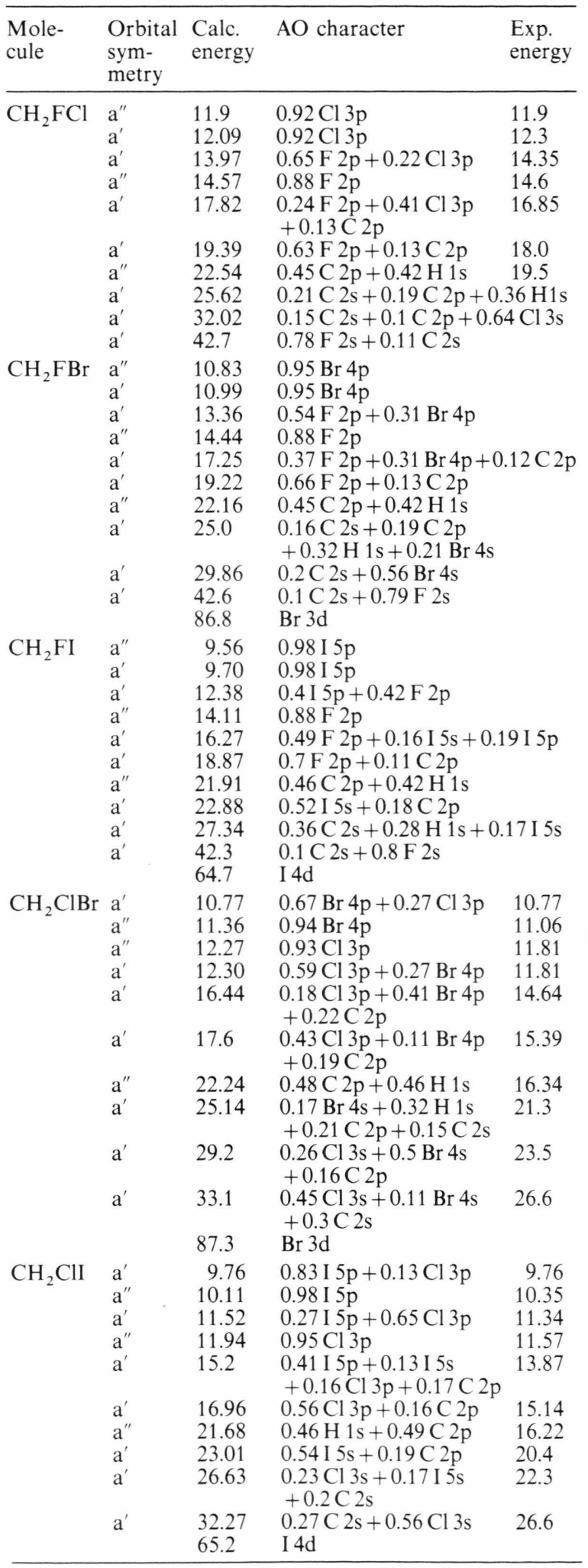

Table 1. (continued).

\begin{tabular}{|c|c|c|c|c|}
\hline $\begin{array}{l}\text { Mole- } \\
\text { cule }\end{array}$ & $\begin{array}{l}\text { Orbital } \\
\text { sym- } \\
\text { metry }\end{array}$ & $\begin{array}{l}\text { Calc. } \\
\text { energy }\end{array}$ & AO character & $\begin{array}{l}\text { Exp. } \\
\text { energy }\end{array}$ \\
\hline $\mathrm{CH}_{2} \mathrm{BrI}$ & $\begin{array}{l}\mathrm{a}^{\prime} \\
\mathrm{a}^{\prime \prime} \\
\mathrm{a}^{\prime} \\
\mathrm{a}^{\prime \prime} \\
\mathrm{a}^{\prime} \\
\mathrm{a}^{\prime} \\
\mathrm{a}^{\prime \prime} \\
\mathrm{a}^{\prime} \\
\mathrm{a}^{\prime} \\
\mathrm{a}^{\prime}\end{array}$ & $\begin{array}{l}9.38 \\
10.01 \\
10.94 \\
11.0 \\
14.71 \\
16.12 \\
21.28 \\
22.70 \\
25.83 \\
30.54 \\
65.0 \\
86.9\end{array}$ & 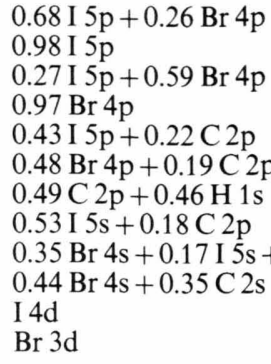 & $12 \mathrm{C} 2 \mathrm{~s}$ \\
\hline
\end{tabular}

a The EFH eigenvalues are linearly shifted so that HOMO binding energy equals the measured ionization energy.

b Only AO characters $>10 \%$ are included in the Table.

basis sets instead are negligible $(<0.5 \mathrm{eV}$ in binding energy and $<1 \%$ in atomic orbital character). It seems adequate therefore to use double zeta sets and achieve savings in computer time if necessary. The experimental binding energies deduced from photoelectron spectra are also included in Table 1.

The comparison of experimental with calculated binding energies (via Koopmans' approximation) shows the latter ones to be consistently too large. The overestimation, while quite small for halogen lone pair ionizations, gradually becomes larger reaching discrepancies of around $10 \mathrm{eV}$ for inner shell d orbitals of bromine and iodine. Similar discrepancies were observed by Zwanziger and Reinhold [3] in fluoromethanes.

The assignment of molecular orbitals derived from the present calculations is in excellent agreement with the one obtained empirically from photoelectron spectra of $\mathrm{CH}_{2} \mathrm{FCl}, \mathrm{CH}_{2} \mathrm{BrCl}$ and $\mathrm{CH}_{2} \mathrm{ClI}[1,2]$. The assignment proposed in this work for the three remaining dihalides whose spectra have not yet been reported thus seems fairly reliable.

It is informative to comment on several aspects of photoelectron spectra reported by Doucet et al. [1] and Novak et al. [2].

The photoelectron spectrum of $\mathrm{CH}_{2} \mathrm{FCl}$ reported by Doucet et al. has been interpreted in a qualitative way only, without description of MO symmetries or characters. The first two bands in the spectrum (with lowest ionization energies) have been assigned to chlorine lone pair ionization, which is confirmed by 


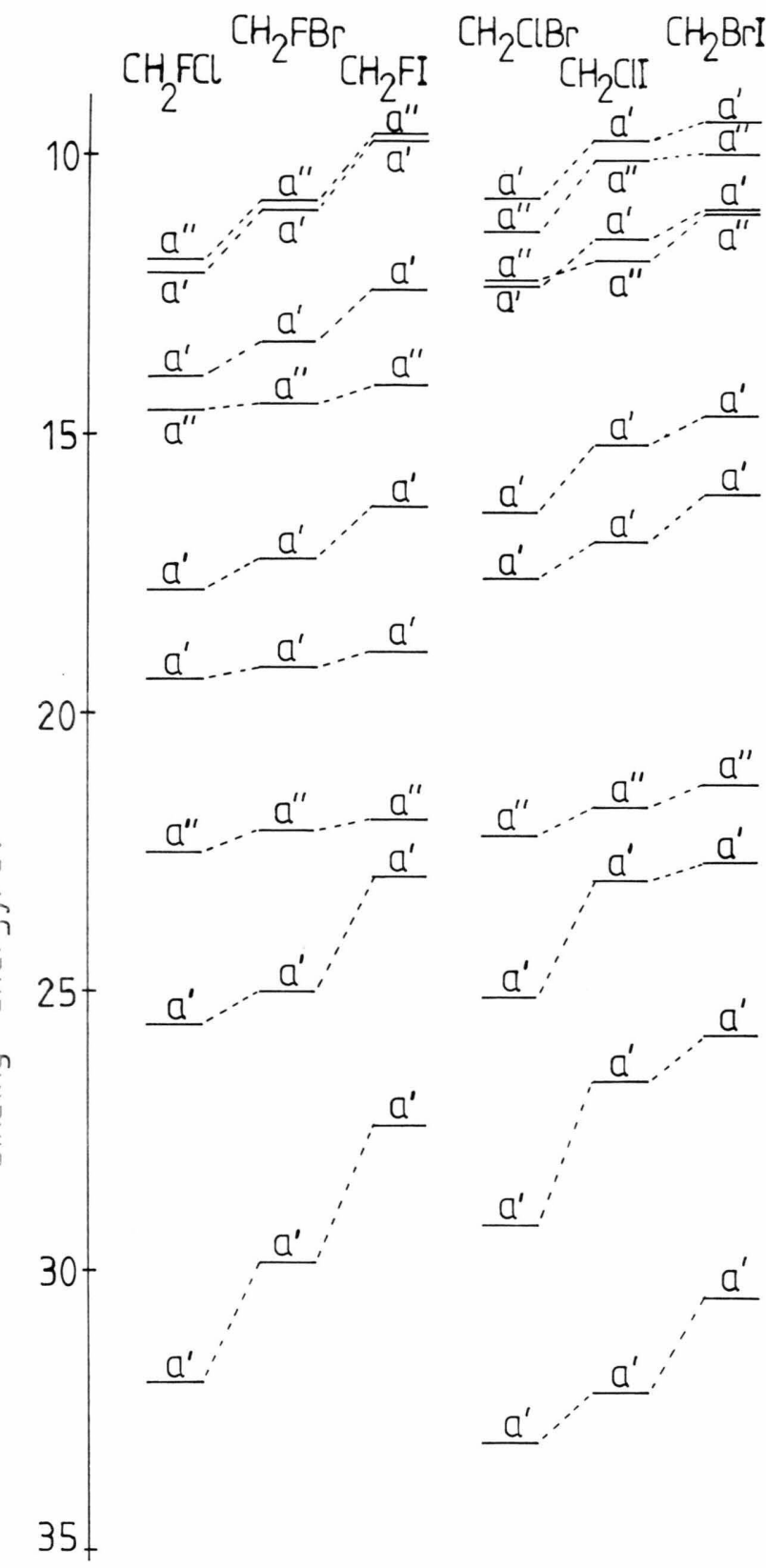

Fig. 1. Correlation diagram for the occupied MOs deduced from EFH calculations via Koopmans' approximation.

our calculation. The next group of bands at around $14 \mathrm{eV}$ and $16-19 \mathrm{eV}$ was described as corresponding to $\mathrm{CCl}, \mathrm{CH}$ and $\mathrm{CF}$ bonding orbital ionization. Our calculations suggest a more complex picture. The $14 \mathrm{eV}$ band should be associated with the orbitals of predominantly $\mathrm{F} 2 \mathrm{p}$ and $\mathrm{Cl} 3 \mathrm{p}$ character (Table 1 ). Similar orbital character pertains to bands at 16.85 and $18.0 \mathrm{eV}$, which can be described as $\mathrm{CCl}$ and $\mathrm{CF}$ bonding orbitals, while the last band at $19.5 \mathrm{eV}$ corresponds to predominantly $\mathrm{CH}$ bonding orbital. The orbitals with higher binding energies appear to be of strongly mixed character with the exception of the highest which possesses predominantly $\mathrm{F} 2 \mathrm{~s}$ composition.

It should be born in mind that the Koopmans' approximation breaks down at high binding energies $(>20 \mathrm{eV})$ with many-body effects causing the appearance of satellite bands and general redistribution of photoelectron intensities. Consequently the electronic structure calculated for this energy region must be regarded as of qualitative value only.

Our interpretation of bonding characteristics of $\mathrm{CH}_{2} \mathrm{FCl}$ appears in good agreement with results reported by $\mathrm{Li}$ et al. [10] for their MS X $\alpha$ calculations on $\mathrm{CH}_{2} \mathrm{~F}_{2}$ and $\mathrm{CH}_{2} \mathrm{Cl}_{2}$.

The photoelectron spectra of $\mathrm{CH}_{2} \mathrm{BrCl}$ and $\mathrm{CH}_{2} \mathrm{ClI}$ have been assigned by Novak et al. [2], and their empirically derived assignments fully agree with ours. A slightly different interpretation of bands in the $20-27 \mathrm{eV}$ region is worth commenting upon. The 3 bands in this region correspond to ionization from orbitals with strongly mixed $\mathrm{I} 5 \mathrm{~s}, \mathrm{Br} 4 \mathrm{~s}, \mathrm{Cl} 3 \mathrm{~s}$ and $\mathrm{C} 2 \mathrm{~s}$ character as revealed by our calculations (Table 1). It should be emphasized that these orbitals cannot be described in terms of single $\mathrm{I} 5 \mathrm{~s}, \mathrm{Br} 4 \mathrm{~s}$ or $\mathrm{Cl} 3 \mathrm{~s}$ character due to heavy mixing taking place in the region.

The suggestion made by Novak et al. regarding the shape of the photoionization asymmetry parameter $\beta$ for lone pair ionization can now be reexamined in the light of the present calculations. The difference in $\beta$ curves between $\mathrm{CH}_{2} \mathrm{BrCl}$ and $\mathrm{CH}_{2} \mathrm{ClI}$ should indeed be attributed to the different shapes of constituent $\beta$ curves for $\mathrm{Br}$ and I lone pairs and not to the extent of halogen mixing. Table 1 shows that the mixing, while considerable in both dihalides, is actually slightly higher in $\mathrm{CH}_{2} \mathrm{BrCl}$. On the basis of mixing considerations alone we would expect stronger $\beta$ oscillations for $\mathrm{CH}_{2} \mathrm{BrCl}$ than for $\mathrm{CH}_{2} \mathrm{ClI}$, which is not observed experimentally. The present results appear to support our original argument about the importance of individual curve shapes in determining the final $\beta$ variation.

Figure 1 shows the general trends in eigenvalues for six dihalides. As expected, the introduction of a less electronegative halogen into the molecule inductively 
shifts the energy levels towards lower ionization energies. The inner shell $\mathrm{Br} 3 \mathrm{~d}$ and $\mathrm{I} 4 \mathrm{~d}$ binding energies seem to be unaffected by substituent changes as can be expected from orbitals with predominantly atomic character. The most manifest shifts occur for orbitals with significant heavy atom s character possibly due to their spherically symmetrical shape, which permits overlap and interaction with several other bonding orbitals in the molecule ("through-bond" interaction). In conclusion, we believe that the EFH method provides a useful and convenient method to study small molecules with several heavy atoms and of low symmetry provided large enough basis sets and carefully

[1] J. Doucet, P. Savageau, and C. Sandorfy, J. Chem. Phys. 58, 3708 (1973).

[2] I. Novak, J. M. Benson, and A. W. Potts, Chem Phys. 107, 129 (1986).

[3] Ch. Zwanziger and J. Reinhold, Chem. Phys. Lett. 69, 545 (1980).

[4] E. Clementi and C. Roetti, At. Data Nucl. Data Tables 14, 177 (1974).

[5] I. Ohkoshi, and Y. Niide, and M. Takano, J. Mol. Spectrosc. 124, 118 (1987). selected molecular geometries are adopted in the calculation. The results described in this work will hopefully stimulate further study of low symmetry halomethanes.

\section{Acknowledgements}

The author would like to thank Dr. G. J. Long from Department of Chemistry, University of Missouri Rolla for kindly providing the Fenske-Hall program and "R. Bošković" Institute, Zagreb for leave of absence.

[6] P. A. Curnuck and J. Sheridan, Nature London 202, 591 (1964).

[7] N. Muller, J. Amer. Chem. Soc. 75, 860 (1953).

[8] M. Zaki El-Sabban, A. Danti, and B. J. Zwolinski, J. Chem. Phys. 44, 1770 (1966).

[9] Tables of Interatomic Distances and Configuration in Molecules and Ions, L. E. Sutton (ed.), Special Publication No.11, The Chemical Society, London 1958.

[10] D. Li, J. K. Zhu, J. Q. Li, and Y. K. Pan, J. Electron Spectrosc. 34, 1 (1984). 